\title{
PENGARUH SEXUAL SATISFACTION TERHADAP TINGKAT KESEHATAN MENTAL IBU RUMAH TANGGA DI SUMBAWA
}

\author{
Fitra Hasri Rosandi ${ }^{1}$, Roni Hartono ${ }^{2}$, Risydah Amani Mujahidah ${ }^{3}$
}

1,2,3*Fakultas Psikologi Universitas Teknologi Sumbawa

*Corresponding Author email: ${ }^{*}$ fitra.hasri.rosandi@uts.ac.id, ${ }^{2}$ roni.hartono@uts.ac.id

\begin{tabular}{ll}
\hline & Abstrak \\
\cline { 2 - 3 } Diterima : & Sexual satisfaction merupakan perasaan puas yang didapatkan dari aktivitas seksual \\
Bulan Januari & antara suami dan istri. Pada beberapa kasus ditemukan bahwa istri cenderung tidak \\
2021 & mendapatkan sexual satisfaction.Hal tersebut dapat menimbulkan dampak negatif bagi \\
& istri maupun kedua belah pihak karena sexual satisfaction merupakan indikator \\
& kebahagian pernikahan dan sumber energi psikis individu. Oleh karena itu, penelitian ini \\
& bertujuan untuk mengetahui pengaruh sexual satisfaction terhadap tingkat kesehatan \\
Dental ibu rumah tangga. & \\
Bulan Februari & Penelitian ini menggunakan pendekatan kuantitatif dengan jenis penelitian kausal \\
2021 & komparatif. Data dikumpulkan menggunakan skala yaitu skala kepuasan seksual \\
& NSSS) dan skala kesehatan mental (WEMWBS). Adapun jumlah subyek penelitian \\
Keyword: & yang ditentukan berdasarkan teknik pengambilan sampel berbentuk purposive sampling \\
Sexual & dan rumus slovin sebagai penentu besaran jumlah sampel. \\
satisfaction, & Hasil dari penelitian ini adalah dari hasil uji analisis regresi didapatkan nilai signifikansi \\
Kesehatan & sebesar 0,000<0,005 dan koefisien determinasi (R square) sebesar 0,224 serta koefisien \\
Mental,Ibu & regresi x sebesar 0,267. Hal tersebut menunjukan bahwa adanya pengaruh sexual \\
Rumah Tangga & satisfaction sebesar 22,4\% terhadap tingkat kesehatan mental ibu rumah tangga dan 70,6 \\
& \% dipengaruhi oleh faktor lain seperti lingkungan, kondisi ekonomi dan kematangan \\
& berfikir.
\end{tabular}

\section{PENDAHULUAN}

Kebutuhan seks merupakan salah satu kebutuhan fisiologis manusia yang berisifat sebagai motivator dalam aspek kehidupan (Boeree, 2016). Oleh karena itu, kebutuhan seks memiliki nilai penting bagi keberlangsungan hidup individu. Namun, Cara pemenuhan kebutuhan seks memiliki aturan yang disesuaikan dengan hukum, budaya, agama dan norma yang berlaku di masyarakat. Hal tersebut karena relasi seks mengandung unsurunsur etis dan susila yang berarti baik, bersih serta bertanggung jawab karena melibatkan terjadinya keturunan (Kartono, 2007). Salah satu aturan yang dimaksudkan adalah adanya ikatan pernikahan antara pria dan wanita. Selain dalam segi aturan pemenuhan, indikator yang menentukan bahwa kebutuhan seksual individu telah terpenuhi adalah dengan dirasakannya sexual satisfaction oleh kedua belah pihak yaitu suami dan istri.

Sexual satisfaction jika ditinjau dari definisi adalah kesatuan fisik dan psikis yang dicapai kedua belah pihak sebagai penyebar tekad kesatuan suami istri serta lepasnya ketegangan dan rasa tidak menyenangkan atau tidak enak diseluruh badan (Kartono, 2007). Selanjutnya, menurut Stulhofer dkk (2010) sexual satisfaction merupakan perasaan senang dan puas yang dirasakan individu mengenai sensasi sexual, kesadaran secara sexual, pertukaran sexual, kedekatan emosional dan aktivitas sexual. Berdasarkan uraian pengertian diatas, dapat disimpulkan bahwa sexual satisfaction merupakan perasaan puas yang dicapai karena adanya kesatuan fisik berupa hubungan intim secara fisik antara suami dan istri serta meningkatnya kedekatan emosional antara kedua belah pihak sebagai respon positif dalam aktifitas sexual.

Namun pada praktiknya, relasi seksual antara pria dan wanita membutuhkan penyesuaian. Hal tersebut dikarenakan pria dan wanita memiliki perbedaan baik dari segi fisik dan respon seksual (Hurlock, 2015). Salah satu perbedaan yang ada adalah kemampuan wanita dalam mencapai fase orgasme cenderung memerlukan waktu yang lebih lambat dibandingkan seorang pria (Boeree, 2016). Pada beberapa kasus pria cenderung kurang memperhatikan perbedaan tersebut dan cenderung mencapai fase orgasme tanpa menunggu pihak wanita. Akibatnya sang istri tidak mampu mencapai fase tersebut dan akibatnya kurang merasakan sexual satisfaction.

Kasus tersebut sesuai dengan data awal yang didapatkan oleh peneliti di salah satu wilayah di Sumbawa, bahwa para ibu rumah tangga mengeluhkan aktivitas seksualnya karena suami yang cenderung lebih mendominasi dan acuh pada 
hak seksual istri. Selain itu, beberapa mengeluhkan jika sang suami cenderung memaksakan kehendak dalam melakukan aktivitas seksual dan tidak segan memberikan ancaman ataupun hukunan fisik maupun verbal pada istrinya. Komnas perempuan mencatat bahwa terdapat 2.979 kasus yang tercatat di tahun 2017 sebagai kasus kekerasan sexual di ranah KDRT atau relasi personal yang menimpa sejumlah perempuan di Indonesia. Meskipun motif dan latar belakang korban kasus tersebut beragam, namun tidak dapat dipungkiri jika salah satu faktor terjadinya tindak kekerasan tersebut adalah masalah pemenuhan kebutuhan sexual (www.cnnindonesia.com, diakses pada 20 Oktober 2019).

Dampak negatif dari ketidak selarasan aktivitas seksual antara suami istri dimana pihak istri tidak mendapatkan sexual satisfaction dalam aktivitas seksualnya, maka dapat menimbulkan masalah seperti disfungsi seksual (frigiditas) dan masalah kesehatan mental.

Menurut seorang ahli kesehatan Merriam Webster (Dewi, 2012 ), kesehatan mental merupakan suatu keadaan emosional dan psikologis yang baik, dimana individu dapat memanfaatkan kemampuan kognisi dan emosi serta berfungsi dalam komunitasnya, dan memenuhi kebutuhan hidupnya sehari-hari.

Peran seorang istri dalam sebuah keluarga tidak hanya sebagai patner hidup seorang suami, namun peran istri juga sebagai ibu rumah tangga yang tergabung dalam bagian komponen keluarga dan memiliki peran untuk menunjang ketahanan dan kesejahteraan kesehatan mental keluarga (Rochman, 2010). Oleh karena itu, jika seorang istri mengalami penurunan kondisi kesehatan mental maka akan berdampak pada kondisi kehidupan pernikahan dan keluarganya.

\section{LANDASAN TEORI}

\section{Definisi Sexual Satisfaction}

Sexual satisfaction adalah perasaan senang dan puas yang dirasakan individu mengenai sensasi sexual, kesadaran secara sexual, pertukaran sexual, kedekatan emosional dan aktivitas sexual (Stulhofer, 2010). Sedangkan menurut Kartono (2007) sexual satisfaction adalah bentuk kesatuan fisik dan psikis yang dicapai oleh kedua belah pihak sebagai penyebar tekad kesatuan suami istri serta lepasnya ketengangan dan rasa tidak menyenangkan atau tidak enak di seluruh badan. Kemudian menurut Kinsey (Avianti, 2011) sexual satisfaction adalah respon yang menyenangkan dengan berkurangnya ketegangan serta puncak dari kepuasan fisik dan emosi dalam aktivitas sexual yang disebabkan karena tercapainya ejakulasi dan orgasme secara bersama-sama sebagai puncak hubungan sexual.

Regina \& Malinton (2001) menambahkan bahwa sexual satisfaction adalah kepuasan suami istri dalam melakukan hubungan sexual sebagai kesatuan fisik dan psikis dari kedua belah pihak. Sedangkan menurut Putu (Khotimah, 2017) sexual satisfaction disini tidak hanya hubungan intim suami istri saja, tetapi meliputi kedekatan secara emosional, komunikasi atau keterbukaan seks, kepuasan seutuhnya dalam pernikahan dan kualitas hubungan pernikahan. Maka sexual satisfaction merupakan indikator penting dari sebuah kesuksesan pernikahan dan berdampak pada kelangsungan hidup dan kesehatan keluarga (Shahhosseini, 2014).

Berdasarkan dari uraian di atas, maka sexual satisfaction dapat didefinisikan sebagai respon positif individu yang berbentuk rasa puas dan didapatkan dari aktivitas sexual dengan melibatkan adanya kesatuan fisik berupa hubungan intim antara suami istri serta kedekatan emosional dan kenyamanan psikis antara kedua belah pihak. Definisi tersebut sejalan dengan tujuan aktivitas seksual yang dikemukaan oleh Kartono ( (2007) bahwa tujuan aktivitas seksual yaitu reproduksi, menyatakan afeksi atau cinta kasih (relasi) dan mendapatkan kesenangan (rekreasi). Hal tersebut menunjukan bahwa sexual satisfaction merupakan salah satu hal penting yang harus dicapai oleh kedua belah pihak dalam melakukan aktivitas sexual agar terjalin hubungan yang positif dan harmonis dalam kehidupan pernikahan.

\section{Definisi Kesehatan Mental}

Kesehatan mental secara etimologis berasal dari dua kata yaitu sehat dan mental. Sehat menurut kamus besar bahasa Indonesia (Alwi Hasan, 2005) berarti baik seluruh badan serta sebagian bagiannya. Sehat secara umum dapat dipahami sebagai kesejahteraan secara penuh baik secara fisik, mental maupun sosial, tidak hanya bebas dari penyakit atau keadaan lemah. Sedanngkan mental yang berasal dari bahasa latin yaitu mens, mentis yang artinya jiwa, nyawa, sukma, roh, semangat (Dewi, 2012 ) maka kesehatan mental berarti keadaan jiwa yang baik dan dapat berfungsi secara sempurna.

Daradjat (2001) menyatakan bahwa ada banyak definisi tentang kesehatan mental yang diberikan para ahli, sesuai dengan pandangan dan bidangnya masing-masing. Definisi tersebut antara lain: 1). kesehatan mental adalah terhindarnya orang dari gejala-gejala gangguan jiwa (neurose) dan dari gejala-gejala penyakit jiwa (psychose); 2). kesehatan mental adalah kemampuan untuk menyesuaikan diri dengan diri sendiri, dengan orang lain dan masyarakat serta lingkungan di mana ia hidup; 3). kesehatan mental adalah pengetahuan dan perbuatan yang bertujuan untuk mengembangkan dan memanfaatkan segala potensi, bakat dan pembawaan yang ada semaksimal mungkin, sehingga membawa kepada kebahagiaan diri dan orang lain; serta terhindar dari 
gangguan dan penyakit jiwa; 4). kesehatan mental adalah terwujudnya keharmonisan yang sungguh-sungguh antara fungsi-fungsi jiwa, serta mempunyai kesanggupan untuk menghadapi problem-problem biasa yang terjadi, dan merasakan secara positif kebahagiaan dan kemampuan dirinya.

Almeida (Hadjam, 2011) mengatakan

bahwa kesehatan mental bukan sekedar terbebasnya individu dari berbagai macam gangguan psikologis, tetapi lebih dari itu, kesehatan mental berkaitan dengan kapasitas dan kualitas dimana individu mampu beradaptasi dengan perubahan, memanajemen situasi yang krisis, mendemonstrasikan hubungan yang bermakna dengan individu lain dan menikmati kehidupan. Seorang ahli kesehatan Merriam Webster (Dewi, 2012 ), menerangkan bahwa kesehatan mental merupakan suatu keadaan emosional dan psikologis yang baik, di mana individu dapat memanfaatkan kemampuan kognisi dan emosi, berfungsi dalam komunitasnya, dan memenuhi kebutuhan hidupnya sehari-hari. Karl Menninger (Dewi, 2012 ) menambahkan bahwa individu yang sehat mentalnya adalah mereka yang memiliki kemampuan untuk menahan diri, menunjukan kecerdasan, berperilaku dengan menenggang perasaan orang lain, serta memiliki sikap hidup yang bahagia.

\section{MATODE PENELITIAN}

Penelitian ini menggunakan metode pendekatan kuantitatif kausal komparatif. Populasi dalam penelitian ini adalah ibu rumah tangga yang bertempat tinggal di PPN Bukit Indah Sumbawa dengan jumlah 818.Teknik pengambilan sampel menggunakan teknik purposive sampling dengan memberikan kriteria khusus pada sampel dan penentuan Jumlah sampel secara representative menggunakan rumus slovin yang menghasilkan jumlah sampel sebesar 89 ibu rumah tangga. Adapun instrument penelitian yang digunkan adalah (1) Skala NSSS (New Sexual Satisfaction Scale) yang dikembangkan oleh Aleksander Stulhofer dkk (2010) dengan nilai koefisien reliabilitas cronbach's alpha yang didapatkan dari hasil uji coba ulang sebesar 0,96. (2) Skala WEMWBS (The Warwick-Edinbrugh Mental Well-Being Scale) yang pernah diuji oleh Tennant dkk (2007) dengan skor reliabilitas dari hasil uji coba ulang sebesar 0,84 ..

\section{HASIL DAN PEMBAHASAN}

\section{a. Deskripsi Tingkat Sexual Satisfaction}

Gambaran data dari hasil skala NSSS dapat dilihat pada tabel berikut:

\section{Tabel 4.1}

\section{Distribusi Data Sexual satisfaction}

\begin{tabular}{|l|r|r|r|r|r|r|r|}
\hline & $\mathrm{N}$ & Range & Minimum & $\begin{array}{c}\text { Maxim } \\
\text { um }\end{array}$ & Mean & $\begin{array}{c}\text { Std. } \\
\text { Deviation }\end{array}$ & $\begin{array}{c}\text { Varian } \\
\text { ce }\end{array}$ \\
\hline $\begin{array}{l}\text { Sexual } \\
\text { satisfaction } \\
\begin{array}{l}\text { Valid N } \\
\text { (listwise) }\end{array}\end{array}$ & 89 & 80.0 & 20.00 & 100 & 71.2 & 14.02 & 196.6 \\
\hline
\end{tabular}

Berdasarkan tabel di atas, diketahui bahwa dari 89 subyek ibu rumah tangga nilai minimal yang didapat dari skala sexual satisfaction sebesar 20. Sedangkan nilai maksimal yang didapat sebesar 100, sehingga rentang (range) nilai antara nilai minimal dengan nilai maksimal adalah sebesar 80 . Selain itu, nilai rata-rata (mean) yang didapatkan sebesar 71,26, nilai keragaman data (variance) sebesar 196,676 dan nilai standar deviasi sebesar 14,02 .

Tingkat sexual satisfaction ibu rumah tangga di Sumbawa dibagi menjadi lima kategorisasi yaitu sangat tinggi, tinggi, sedang, rendah dan sangat rendah. Adapun distribusi frekuensi kategori tingkat sexual satisfaction ibu rumah tangga di Sumbawa sebagai berikut:

Tabel 4.2

Distribusi Frekuensi Kategori Sexual satisfaction

\begin{tabular}{|l|r|r|r|r|}
\hline & $\begin{array}{r}\text { Freque } \\
\text { ncy }\end{array}$ & $\begin{array}{c}\text { Percen } \\
\mathrm{t}\end{array}$ & $\begin{array}{c}\text { Valid } \\
\text { Percent }\end{array}$ & $\begin{array}{r}\text { Cumulativ } \\
\text { e Percent }\end{array}$ \\
\hline Valid Sangat & & & & \\
Tinggi & 8 & 9.0 & 9.0 & 9.0 \\
Tinggi & 21 & 23.6 & 23.6 & 32.6 \\
Sedang & 31 & 34.8 & 34.8 & 67.4 \\
Rendah & 26 & 29.2 & 29.2 & 96.6 \\
Sangat & 3 & 3.4 & 3.4 & 100.0 \\
Rendah & 89 & 100.0 & 100.0 & \\
Total & & & \\
\hline
\end{tabular}

Berdasarkan tabel dan diagram di atas, diketahui bahwa tingkat sexual satisfaction dari 89 subyek ibu rumah tangga, terdapat 8 ibu rumah tangga (9\%) yang berada pada kategori sangat tinggi. Selanjutnya, 21ibu rumah tangga $(23,6 \%)$ berada pada kategori tinggi, 31 ibu rumah tangga (34\%) berada pada kategori sedang, 26 ibu rumah tangga $(29,2 \%)$ berada pada kategori rendah dan 3 ibu rumah tangga $(3,4 \%)$ berada pada kategori sangat rendah. Jika disimpulkan, distribusi frekuensi dari skala sexual satisfaction secara umum berada pada kategori sedang sebanyak 31 ibu rumah tangga (34\%).

Berdasarkan hasil perbandingan kategori rerata aspek, diketahui bahwa kelima aspek berada pada interval yang sama dengan nilai skor yang berbeda tipis. Adapun nilai rerata yang didapat yaitu sexual sensation memiliki skor rerata yang sama dengan sexual activity sebesar 3,53, sexual 
awareness dengan skor rerata sebesar 3,58, sexual exchange dengan skor rerata sebesar 3,59 dan emotional closeness dengan skor rerata aspek sebesar 3,52. Dari uraian skor rerata tersebut, maka diketahui rerata keseluruhan aspek pada skala sexual satisfaction sebanyak 3,55 dan berada pada kategori tinggi. Selain itu, terdapat satu aspek yang memiliki skor rerata paling tinggi yaitu aspek sexual exchange sehingga berarti aspek tersebut merupakan aspek yang dominan.

\section{b. Deskripsi Tingkat Kesehatan Mental}

Gambaran data tingkat kesehatan mental ibu rumah tangga di Sumbawa, dapat dilihat pada tabel berikut:

\section{Tabel 4.4}

\section{Distribusi Data Kesehatan Mental}

Berdasarkan tabel di atas, menerangkan bahwa dari 89 subyek ibu rumah tangga diketahui nilai minimal dari skala kesehatan mental sebesar 32, nilai maksimum sebesar 70, rentang (range) nilai antara nilai minimal dengan nilai maksimum skala kesehatan mental adalah sebesar 38. Adapun

\begin{tabular}{|c|c|c|c|c|c|c|c|}
\hline & $\mathrm{N}$ & $\begin{array}{c}\text { Rang } \\
\mathrm{e}\end{array}$ & $\begin{array}{c}\text { Minim } \\
\text { um }\end{array}$ & $\begin{array}{l}\text { Maxi } \\
\text { mum }\end{array}$ & Mean & $\begin{array}{c}\text { Std. } \\
\text { Deviatio } \\
\mathrm{n}\end{array}$ & \begin{tabular}{|c|} 
Varia \\
nce
\end{tabular} \\
\hline $\begin{array}{l}\text { Kesehatan } \\
\text { Mental } \\
\text { Valid N } \\
\text { (listwise) }\end{array}$ & 89 & 38.00 & 32.00 & 70.00 & $\begin{array}{r}55.13 \\
48\end{array}$ & 7.85984 & $\begin{array}{r}61.77 \\
7\end{array}$ \\
\hline
\end{tabular}

nilai rata-rata (mean) yang didapatkan sebesar 55,13 dan nilai keragaman data (variance) sebesar 7,85 serta nilai standar deviasi sebesar 61,77.

Tingkat kesehatan mental pada ibu rumah tangga dalam penelitian ini dibagi menjadi lima kategori yaitu sangat tinggi, tinggi, sedang, rendah dan sangat rendah. Adapun distribusi frekuensi kategori tingkat kesehatan ibu rumah tangga PPN Bukit indah sebagai berikut:

Tabel 4.5

Distribusi Frekuensi kesehatan Mental

\begin{tabular}{|r|r|r|r|r|}
\hline & $\begin{array}{r}\text { Frequ } \\
\text { ency }\end{array}$ & $\begin{array}{r}\text { Perce } \\
\mathrm{nt}\end{array}$ & $\begin{array}{c}\text { Valid } \\
\text { Percent }\end{array}$ & $\begin{array}{c}\text { Cumulati } \\
\text { ve } \\
\text { Percent }\end{array}$ \\
\hline Valid Sangat & 6 & 6.7 & 6.7 & 6.7 \\
Tiinggi & 27 & 30.3 & 30.3 & 37.1 \\
Tinggi & 33 & 37.1 & 37.1 & 74.2 \\
Sedang & 17 & 19.1 & 19.1 & 93.3 \\
Rendah & 6 & 6.7 & 6.7 & 100.0 \\
Sangat & 89 & 100.0 & 100.0 & \\
Rendah & & \\
Total & &
\end{tabular}

Berdasarkan tabel dan diagram di atas, menunjukan kategori tingkat kesehatan mental dari 89 subyek ibu rumah tangga di Sumbawa bahwa teradapat 6 ibu rumah tangga $(6,7 \%)$ berada pada kategori sangat tinggi. Sedangkan pada empat kategori berikutnya diketahui bahwa 27 subyek ibu rumah tangga $(30,3 \%)$ berada pada kategori tinggi, 33 subyek ibu rumah tangga $(37,1 \%)$ berada pada kategori sedang, 17 subyek ibu rumah tangga berada pada kategori rendah dan 6 subyek terakhir $(6,7 \%)$ berada pada kategori sangat rendah.

Hasil dari analisis diatas, disimpulkan bahwa distribusi frekuensi dari skala kesehatan mental secara umum berada pada kategori sedang dengan jumlah 33 subyek ibu rumah tangga $(37,1 \%)$.

Adapun hasil dari perbandingan rerata aspek didapatkan bahwa dari kelima aspek kesehatan mental, aspek keceriaan merupakan aspek yang memiliki skor rerata paling tinggi sebesar 4,48 dan berada pada ketegori sangat tinggi serta menunujukan dominansi aspek yang paling berpengaruh.

\section{c.Pengaruh Sexual Satisfaction Terhadap Kesehatan Mental}

Untuk mengetahui adanya pengaruh dari variable bebas terhadap variable terikat maka dilakukan pengujian data menggunakan analisis regresi dengan bantuan SPSS versi 16.0. Adapun tabel hasil analisis sebagai berikut:

Tabel $\quad 4.6$

Model Summary

\begin{tabular}{|c|c|c|c|c|}
\hline $\begin{array}{l}\text { Mode } \\
\text { I }\end{array}$ & $\mathrm{R}$ & $\begin{array}{c}\mathrm{R} \\
\text { Square }\end{array}$ & $\begin{array}{c}\text { Adjusted R } \\
\text { Square }\end{array}$ & $\begin{array}{l}\text { Std. Error of } \\
\text { the Estimate }\end{array}$ \\
\hline 1 & $.476^{\mathrm{a}}$ & .226 & .217 & 6.95387 \\
\hline
\end{tabular}

b. Dependent Variable: Kesehatan

Mental

Berdasarkan hasil tabel di atas menunjukan bahwa besarnya nilai korelasi atau hubungan (R) sebesar 0,476 dan nilai koefisien determinasi ( $\mathrm{R}$ Square) sebesar 0,226. Hal ini menunjukan bahwa adanya hubungan antara kedua variable dan ada pengaruh dari variabel bebas (sexual satisfaction) terhadap variabel terikat (kesehatan mental) adalah sebesar 22,6\%. Sehingga pengaruh yang diberikan oleh faktor lain sebesar $77,40 \%$. Adapun faktor lain seperti kondisi ekonomi, lingkungan dan kematangan individu.

Tabel 4.7

Tabel di atas menerangkan bahwa nilai signifikansi yang diperoleh sebesar 0,000 yang lebih kecil dari nilai probabilitas sebesar 0,05. Hal

\begin{tabular}{|c|c|c|c|c|c|}
\hline Model & $\begin{array}{l}\text { Unstano } \\
\text { Coeffi } \\
\text { B }\end{array}$ & $\begin{array}{l}\text { ardized } \\
\text { ients } \\
\text { Std. } \\
\text { Error }\end{array}$ & \begin{tabular}{|c}
$\begin{array}{c}\text { Standardi } \\
\text { zed } \\
\text { Coefficie } \\
\text { nts }\end{array}$ \\
Beta
\end{tabular} & $\mathrm{T}$ & Sig. \\
\hline $1 \quad$ (Constant) & 36.140 & 3.839 & & 9.415 & .000 \\
\hline $\begin{array}{l}\text { Sexual } \\
\text { satisfaction }\end{array}$ & .267 & .053 & .476 & 5.042 & .000 \\
\hline
\end{tabular}

a. Dependent Variable: Kesehatan

Mental 
tersebut menunjukan bahwa variabel sexual satisfaction terbukti berpengaruh terhadap variabel kesehatan mental. Selain itu, diketahui nilai constant (a) yang didapat sebesar 36,140 , sedangkan nilai sexual satisfaction (b/ koefisien regresi) sebesar 0,267. Hal tersebut memiliki artian yaitu nilai constant 36,312 adalah nilai konsisten variabel kesehatan mental. Sedangkan koefisien regresi X sebesar 0,267 mengandung artian bahwa setiap penambahan nilai sexual satisfaction, maka nilai kesehatan mental bertambah 0,267. koefisien regresi tersebut bernilai positif, sehingga dapat dikatakan bahwa arah pengaruh variabel sexual satisfaction terhadap variabel kesehatan mental adalah positif.

\section{PEMBAHASAN}

Berdasarkan hasil analisis data ditemukan nilai signifikansi $0,000<0,05$ maka ha diterima dan ho ditolak. Hal tersebut menunjukan bahwa adanya pengaruh dari sexual satisfaction terhadap tingkat kesehatan mental sebesar 22,60\%.

Dari hasil analisis distribusi frekuensi ditemukan bahwa tingkat sexual satisfaction ibu rumah tangga di PPN Bukit indah secara umum berada pada kategori sedang dan berdasarkan distribusi frekuensi kelompok usia pernikahan, tingkat sexual satisfaction yang paling tinggi dirasakan oleh kelompok usia $2-7$ tahun. Sedangkan jika ditinjau dari rerata aspek dimana sexual satisfaction memiliki lima aspek yaitu sexual sensation, sexual awareness, sexual exchange, sexual closeness dan sexual activity. Kelima aspek tersebut hampir memiliki skor rerata yang sama besar, sehingga total skor rerata yang didapat sebesar 3,55 yang menunjukan tingkat rerata aspek sexual satisfaction ibu rumah tangga di PPN Bukit Indah dalam kategori tinggi. Selain itu, salah satu aspek yang paling dominan adalah sexual exchange yang mendapatkan skor rerata sebesar 3,59.

Dominasi aspek tersebut sejalan dengan salah satu penelitian yang dilakukan oleh Avianti dan Hendrati (2011). Hasil dari penelitian tersebut menunjukan bahwa hubungan interpersonal suami istri yang berbentuk keterbukaan komunikasi seksual memiliki pengaruh sebesar 76,4\% dalam meningkatkan sexual satisfaction pada istri.

Sedangkan pada variable kesehatan mental, hasil analisis distribusi frekuensi ditemukan bahwa tingkat kesehatan mental ibu rumah tangga di PPN Bukit Indah secara umum berada pada kategori sedang. Hasil tersebut sesuai dengan hasil analisis distribusi frekuensi yang ditinjau dari rentang usia pernikahan, ditemukan ke empat kelompok usia pernikahan berada pada satu kategori yang sama yaitu kategori sedang. Sedangkan jika ditinjau dari rerata aspek dimana kesehatan mental memiliki lima aspek yaitu keceriaan, kepuasan hidup, fungsi psikologis, hubungan baik dengan orang lain dan relasi diri. Dari kelima aspek tersebut diketahui dari hasil perbandingan kriteria pembanding bahwa aspek keceriaan memiliki skor rerata paling tinggi sebesar 4,48 dengan rerata aspek keseluruhan sebesar 3,99. Oleh karena itu, aspek keceriaan berada pada kategori sangat tinggi dan merupakan aspek yang dominan dalam memberikan pengaruh pada tingkat kesehatan mental ibu rumah tangga di PPN Bukit Indah.

Dominansi aspek keceriaan pada kesehatan mental bersesuaian dengan teori yang dikemukaan oleh Barbara L Fredricson yang menjelaskan bahwa emosi positif dapat membentuk kesehatan mental yang optimal (Rusydi, 2012).

Hasil penelitian ini, sesuai dengan teori yang dikemukaan oleh Kartono (2007), bahwa sexual satisfaction merupakan energi psikis bagi individu dan memberikan vitalitas tubuh untuk menunjang gairah hidup yang positif. Selain itu, Kartono (2000) juga menambahkan bahwa salah satu prinsip pokok dalam menunjang kesehatan mental adalah kepuasan di mana setiap pemenuhan kebutuhan pastinya bertujuan mendapatkan rasa kepuasan dan dari kepuasan tersebut menimbulkan kesadaran nilai diri dan kesadaran penguasaan individu. Dua hal tersebut, merupakan salah satu komponen dari kriteria kesehatan mental yang pernah disusun oleh Abraham maslow (Rochman, 2010)

\section{PENUTUP}

\section{Kesimpulan}

Tingkat sexual satisfaction dan tingkat kesehatan mental ibu rumah tangga di Sumbawa pada umumnya berada pada kategori sedang. Selain itu, pada kelima aspek dari masing-masing variable ditemukan bahwa pada variable sexual satisfaction terdapat satu aspek yang paling dominan yaitu aspek sexual exchange. Sedangkan pada variable kesehatan mental, aspek keceriaan memiliki pengaruh yang dominan dibandingkan keempat aspek lainnya berdasarkan besaran skor rerata yang didapat.

Dari hasil analisis regresi didapatkan nilai signifikansi sebesar 0,000 yang berarti lebih kecil dibandingkan nilai probabilitas sebesar 0,05. Hasil perbandingan tersebut menunjukan bahwa adanya pengaruh sexual satisfaction terhadap kesehatan mental ibu rumah tangga di Sumbawa. Selain itu, besaran pengaruh sexual satisfaction terhadap kesehatan mental adalah $22,60 \%$ dan sisanya $77,40 \%$ dipengaruhi oleh faktor lainnya seperti lingkungan, ekonomi, kematangan emosi dll. Arah pengaruh sexual satisfaction tehadap kesehatan mental adalah positif dan setiap penambahan nilai sexual satisfaction akan bertambah juga nilai kesehatan mental sebesar 0,267. Maka hipotesis penelitian mengungkapkan adanya pengaruh yang signifikan antara sexual satisfaction terhadap 
kesehatan mental, sehingga Ha diterima dan Ho ditolak.

Saran yang dapat diberikan oleh peneliti berdasarkan hasil penelitian di atas sebagai berikut:

1. Bagi Pasangan suami istri Sebaiknya pasangan suami istri lebih memperhatikan dan memiliki keterbukaan dalam pemenuhan kebutuhan seksual atau dalam menjalin relasi seksual yang seimbang. hal tersebut bertujuan agar sexual satisfaction dapat mudah dicapai bersama dan ketahanan kesehatan mental kedua belah pihak dapat terjaga dengan baik.

2. Bagi Peneliti selanjutnya

Bagi peneliti selanjutya yang ingin meneliti lebih dalam terkait sexual satisfaction dan kesehatan mental ibu rumah tangga diharapkan agar memperluas cakupan penelitian dengan mempertimbangkan variabel lain seperti suku, budaya, agama, umur dan kondisi ekonomi yang lebih homogen.

\section{REFERENSI}

Avianti, H. (2011). Pengaruh Keterbukaan Komunikasi Seksual Suami Istri Mengenai Hubungan Seksua Terhadap Kepuasan Seksual Istri. Jurnal Psikologi.
Boeree, G. (2016). General Psychology: Psikologi Kepribadian, Presepsi, Kognisi, Emosi \& Perilaku. Jogjakarta: Prismashopie.

Dewi, K. (2012 ). Buku Ajar Kesehatan Mental. Semarang: Lembaga Penjamin Mutu Pendidikan Universitas Diponegoro.

Hurlock. (2015). Psikologi Perkembangan: Suatu Pendekatan Sepanjang Rentang Kehidupan Edisi Kelima Terjemahan. Jakarta: Erlangga.

Kartono, K. (2007). Psikologi Wanita 2. Bandung: Mandar Maju.

Rochman, K. (2010). Kesehatan Mental. Yogyakarta: Fajar Media Press.

Rochman, K. (2010). Kesehatan Mental. Yogyakarta: Fajar Media Press.

Stulhofer, B. \&. (2010). Decelopment and BIcultural Validation of The New Sexual Satisfaction Scale. Journal of Sex Research, 257-268.

Tennant, A. O. (2007). The Warwick Edinburgh Mental Well-Being Scale (WEWBS): Development \& UK Validation. Blomed Central.

Zulkaida, S. \&. (2013). Studi Deskriptif Mengenai Faktor - Faktor yang Mempengaruhi Kepuasan Perkawinan Pada Istri. UG Journal. 